\title{
Effect of electron beam treatment on the structure and properties of AlCoCrFeNi high-entropy alloy
}

\author{
V. E. Gromov, Dr. Phys.-Math., Prof., Head of Dept. of Natural Sciences', e-mail: gromov@physics.sibsiu.ru \\ Yu.F. Ivanov, Dr. Phys.-Math., Prof., Chief Researcher2,e-mail: yufi55@mail.ru \\ S. V. Konovalov, Dr. Eng., Prof., Head of Dept. of Metals Technology and Aviation Materials ${ }^{3}$, e-mail: ksv@ssau.ru \\ K. A. Osintsev, Post-Graduate Student, Dept. of Metals Technology and Aviation Materials ${ }^{3}$, e-mail: kirilloss@yandex.ru
}

\author{
${ }^{1}$ Siberian State Industrial University, Novokuznetsk, Russia \\ ${ }^{2}$ Institute of High-Current Electronics SB RAS, Tomsk, Russia \\ ${ }^{3}$ Samara National Research University, Samara, Russia
}

\begin{abstract}
In the last decade the attention of scientists in the field of physical material science has been drawn to the study of high entropy alloys. Using wire arc additive manufacturing (WAAM) technology the high-entropy alloy (HEA) AlCoCrFeNi of nonequiatomic composition has been produced (wt. \%: $15.64 \mathrm{Al} ; 7.78 \mathrm{Co} ; 8.87 \mathrm{Cr} ; 22.31 \mathrm{Fe} ; 44.57 \mathrm{Ni}$ ). It is shown by methods of modern material science that the HEA is a polycrystalline material with a grain size $4-15 \mu \mathrm{m}$ along whose grain boundaries the second-phase particles are detected. It is shown by the mapping methods that bulks of grains are enriched in aluminium and nickel while grain boundaries contain chromium and iron. Cobalt is quasi-uniformly distributed in crystal lattice of the manufactured HEA. The material ultimate strength in testing for compression depends on production mode and varies within the interval from 1300 to $1800 \mathrm{MPa}$. The HEA wear parameter amounts to $1.4 \cdot 10^{-4} \mathrm{~mm}^{3} / \mathrm{N} \cdot \mathrm{m}$, friction coefficient -0.65 . In testings for tension the material failure occurred by the mechanism of intragrain cleavage. The formation of brittle cracks along boundaries and in grain boundary junctions i.e. in sites containing the inclusions of second phases is revealed. One of the reasons of HEA increased brittleness is the revealed nonuniform distribution of elements in alloy structure. The HEA's irradiation by pulsed electron beam with energy density of $10-30 \mathrm{~J} / \mathrm{cm}^{2}$ (pulse duration $200 \mu \mathrm{s}$, number of pulses 3) results in material homogenization. High-velocity crystallization of molten surface layer of HEA samples is accompanied by the formation of columnar structure having a submicro-nanocrystalline structure. The HEA irradiation results in the increase in hardness and plasticity of the material. The largest increase (1.6 times) in ultimate strength is obtained in the alloy after electron beam processing with energy density of $30 \mathrm{~J} / \mathrm{cm}^{2}$. Electron beam processing leads to decrease in microhardness of alloy surface layer up to $90 \mu \mathrm{m}$ thick. Key words: wire-arc additive manufacturing, high-entropy alloy, $\mathrm{AlCoCrFeNi}$, structure, properties, atom distribution, friction coefficient, electron-beam treatment.

DOI: $10.17580 /$ cisisr.2021.02.13
\end{abstract}

\section{Introduction}

In last years, a new system of alloys known as highentropy alloys (HEA) has been attracting scientists' attention [1-3]. Unlike traditional alloys high-entropy ones are composed of five and more main elements with a percentage from 5 to 35 at.\% [4-7]. The idea of high-entropy alloys is that atoms of all elements are considered atoms of a dissolved substance, cause deformation of a crystal structure and improve thermodynamic stability of properties related to differences in atomic radii of components. It results in high entropy of a system to further manufacturing a material with unique properties, which are impossible in traditional micro-alloying techniques [8-10].

The original results obtained in the field of HEA are considered in detail in analytical reviews [11-13] where the HEA microstructure, properties, thermodynamics are described, results of modelling of their structure are considered and new variants of methods for obtaining the multi-component alloys are discussed. The HEA studies have shown that it is possible to form in them nanodimensional structures and even amorphous phases due to considerable distortions of lattice caused by difference in the atomic radii of substitution elements [1].
Present day practically all types of such alloys (structural, cryo- and heat resistant, corrosion-resistant, those with special magnetic and electrical properties) as well as compounds (carbides, nitrides, oxides, borides, silicides) are being developed [14]. Improvement of alloy properties can be achieved by treating the surface with concentrated energy flows. The main feature of hardening materials with concentrated energy fluxes, in comparison with the methods of traditional thermal and chemical-thermal treatment, is the nanostructuring of their surface layers. This means a decrease in the scale level of localization of plastic deformation of the surface, which leads to a more uniform distribution of elastic stresses near it under the influence of operational factors. As a result, the probability of nucleation of microcracks in the surface layer leading to failure is significantly reduced. This increases both strength and ductility.

One of the most promising and highly effective methods of surface hardening of products is electron-beam processing $[15,16]$. Electron beam processing provides ultrahigh heating rates (up to $10^{6} \mathrm{~K} / \mathrm{s}$ ) of the surface layer to predetermined temperatures and cooling of the surface layer due to heat removal to the bulk of the material at speeds of $10^{4}-10^{9} \mathrm{~K} / \mathrm{s}$, resulting in the formation of non-uniform submicron nanocrystalline structural phase states. 
The purpose of this work is the investigation of the structure-phase state and properties of high-entropy alloy $\mathrm{AlCoCrFeNi}$ subjected to electron beam treatment.

\section{Material and Methods of Research}

Samples of high-entropy alloys were fabricated via layerby-layer deposition on a steel substrate using wire arc additive inert gas ( $\mathrm{Ar}-99.99 \%)$. An input material was a three-core cable made of an aluminum wire $(\mathrm{Al}-99.95 \%$, diameter $0.5 \mathrm{~mm})$, a chromium-nickel wire $(\mathrm{Cr}-20 \%, \mathrm{Ni}-80 \%$, diameter $0.4 \mathrm{~mm})$ and $\mathrm{Ni}-\mathrm{Co}$ wire $(\mathrm{Co}-17 \%, \mathrm{Fe}-54 \%$, $\mathrm{Ni}-29 \%$, diameter $0.4 \mathrm{~mm}$ ) (Fig. 1a). Layers were deposited in the following conditions: cable supply speed $8 \mathrm{~m} /$ min, voltage $17 \mathrm{~V}$, torch speed $0.3 \mathrm{~m} / \mathrm{min}$, substrate temperature $-523 \mathrm{~K}$. The sample was fabricated as a $60 \times 140 \times 20 \mathrm{~mm}$ parallelepiped and comprised 20 deposited layers in height and 4 layers in width (Fig. 1b).

Elemental and phase composition of the alloy, state of the defective substructure were studied by the methods of scanning electron microscopy (microscope "LEO EVO 50", Carl Zeiss), transmission electron diffraction microscopy manufacturing (WAAM) technology in the atmosphere of an

(instrument JEM 2100, JEOL) and X-ray phase and X-ray structural analysis (X-ray diffractometer Shimadzu XRD 6000 and DRON-7).

The HEA mechanical properties were characterized by microhardness value (microhardness tester HV-1000) and nanohardness value (nanotester NanoScan-4D). Electronbeam processing was performed with the following parameters: energy of accelerated electrons $U=18 \mathrm{keV}$, energy density of electron beam $E_{S}=(10,15,20,25,30) \mathrm{J} / \mathrm{cm}^{2}$, pulse duration of electron beam $\mathrm{f}=200 \mu$ s, pulse number $N=3$. Irradiation was done in vacuum at pressure of residual gas (argon) in setup chamber $p=0.02 \mathrm{~Pa}$.

\section{Results and Discussion}

The images of microstructure of HEA sample crosssection allowed us to determine that deposited layers had dendritic structure. Dendrites are oriented along heat removal direction. Grain sizes vary in the limits from $4 \mu \mathrm{m}$ to $15 \mu \mathrm{m}$ and increase as we approach the interface of deposited layers [17].

The results of the quantitative analysis of the elemental composition of the alloy under study (averaging was carried out over five randomly selected sections)
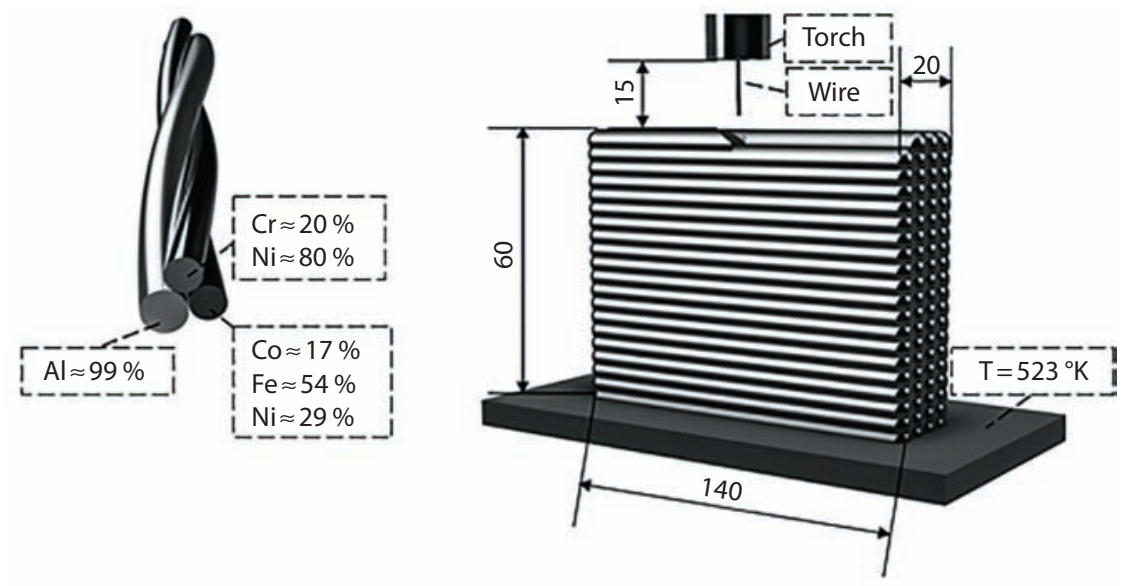

$b$
Fig. 1. Three-core cable used in the study for wire arc additive manufacturing $(a)$, wire arc additive manufacturing scheme (b)
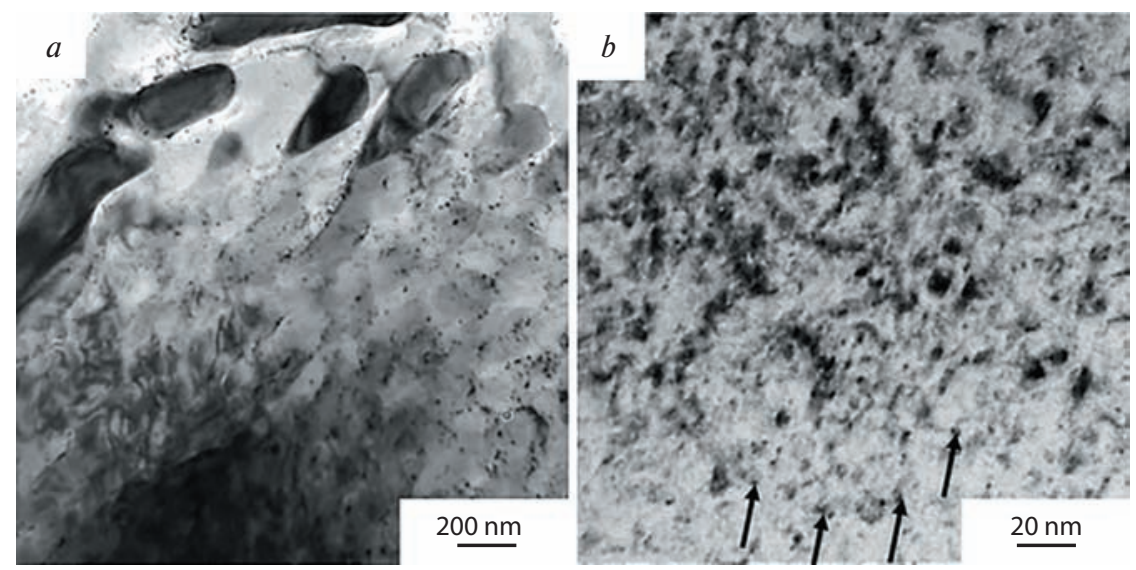

Fig. 2. Electron microscopic images of the HEA structure showed that the main elements of the alloy section under study are aluminum (36.5 at. \%), nickel (33.7 at. \%), iron (16.4 at. \%), chrome (8,6 at. \%) and cobalt (4.9 at. \%).

By mapping methods it is established that near-boundary volumes of the alloy (volumes located along grain boundaries) are enriched in chromium and iron atoms, the grain volume is enriched in nickel and aluminium atoms and cobalt is quasi-uniformly distributed in alloy.

Thermogravimetric analysis allowed us to determine the melting temperature of the produced high-entropy alloy. It is established that melting temperature of produced high-entropy alloy equals to $1495.18^{\circ} \mathrm{C}$.

The structural analysis of the alloy by the methods of transmission electron microscopy allowed to investigate of the distribution of elemental composition, state of defective substructure and morphology of material phases at submicro- and nanodimensional levels. It is detected that inclusions of two dimensional classes: submicron inclusions (Fig. 2a) and nanodimensional inclusions (Fig. $2 \boldsymbol{b}$, particles are indicated by arrows) are present in the alloy.

There are spherical particles along the boundary of cuboidal and bandlike particles. According to the results of a micro-diffraction analysis these 
particles are $(\mathrm{Ni}, \mathrm{Co})_{3} \mathrm{Al}_{4}$ aluminides. Figure 3 shows the data indicating that cuboid particles are nickel aluminides $\left(\mathrm{Al}_{3} \mathrm{Ni}\right)$.

The $4 \%$ increase in microhardness value was found in the area located on boundary with substrate that may be related to the $10 \%$ increase in iron content revealed in the course of layer-by-layer elemental analysis. In the remaining areas value deviates from the average one by no more
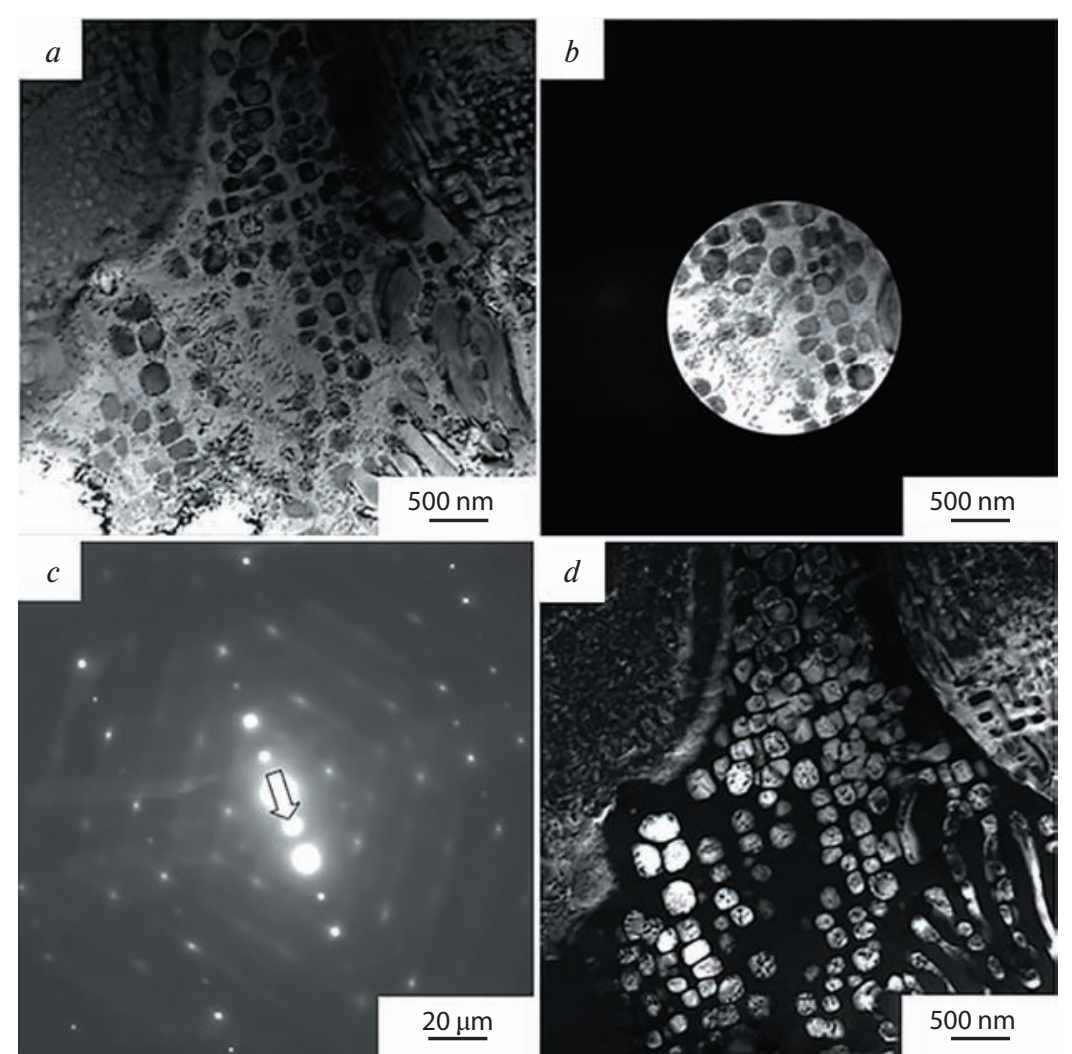

Fig. 3. TEM image of a high-entropy alloy foil; $a, b-$ bright fields; $c$ - electron diffraction pattern obtained on the foil section $(b)$ in the selective diaphragm; $d-$ dark field obtained in the $[011] \mathrm{Al}_{3} \mathrm{Ni}$ reflex. The arrow $(c)$ indicates a reflex, where a dark field was obtained than $2 \%$. As a result of performed studies it is established that the mean microhardness value of the samples amounts to $474 \pm 18 \mathrm{HV}$.

On the average nanohardness of sample under study amounts to $10.4 \pm 0.8 \mathrm{GPa}$ independent of distance to surface. The elastic modulus measured by nanoindentation method amounts $304 \pm 15 \mathrm{GPa}$. It is stated as a result of performed tests that HEA wear factor amounts to $1.4 \times 10^{-4} \mathrm{~mm}^{3} / \mathrm{N} \cdot \mathrm{m}$, friction factor is 0.65 . The results of compression tests of HEA samples showed that the ultimate strength of material is in the interval from 1300 to $1800 \mathrm{MPa}$.

The Young's modulus is in the interval 270-370 GPa. The results of tests for tension at temperature of $20^{\circ} \mathrm{C}$ revealed a brittle failure of obtained samples independent of the place out of which the samples were cut from a solid massive. The failure occurred by the mechanism of intergranular cleavage along the plane located at an angle of $45^{\circ}$ to tension axis. Ultimate tensile strength amounted $4 \mathrm{MPa}$ on the average.

Figures 4 represents images of HEA surface structure being formed in irradiation with pulsed electron beam at different energy density of electron beam. First of all, we emphasize that independent of energy density of electron beam the HEA irradiation is accompanied by fragmentation of sample surface by microcracks' network. The fragments sizes reach several hundred micrometers, essentially increasing in grain sizes of initial alloy. It is evident that microcracks form as a result of relaxation of elastic stresses arising in material surface layer on velocity cooling taking place in conditions of irradiation by pulsed
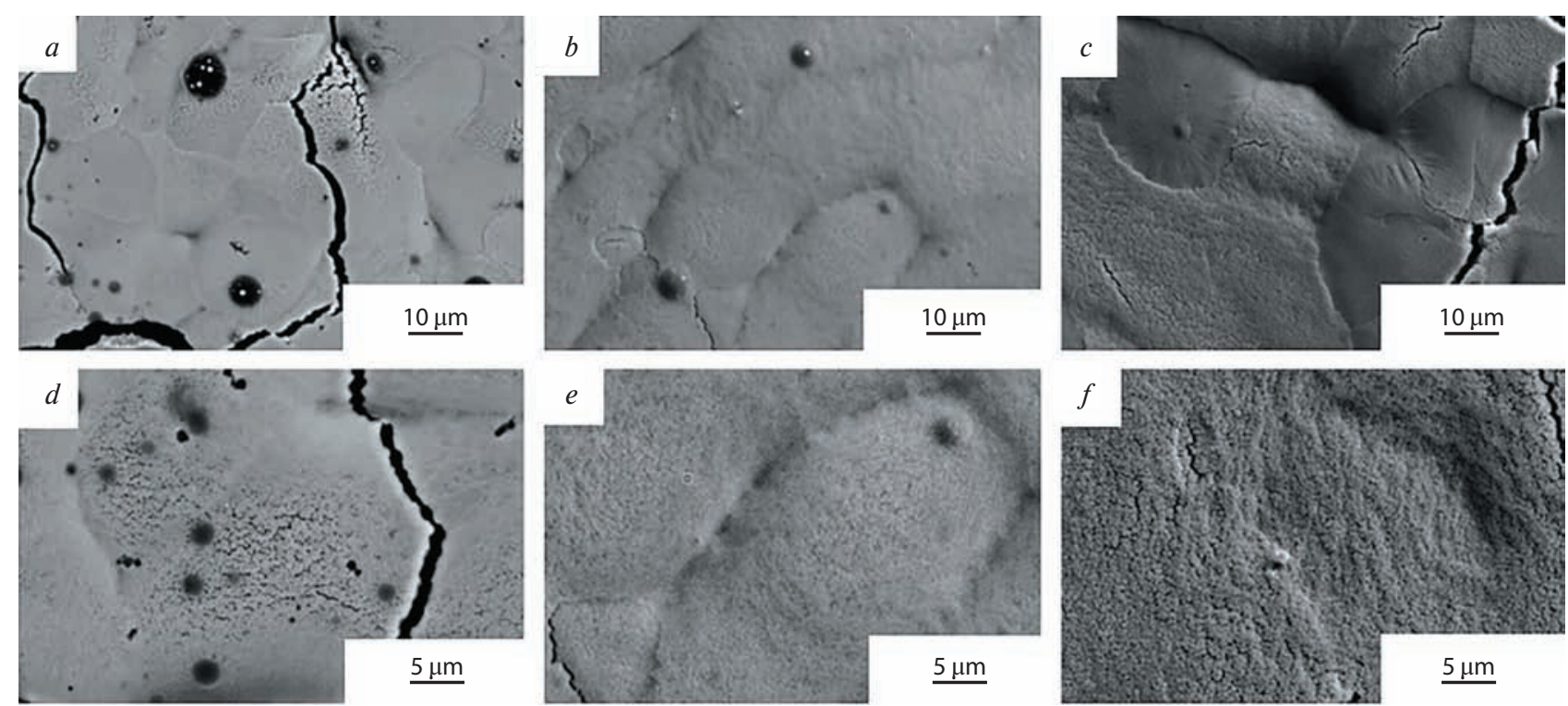

Fig. 4. SEM image of HEA structure being formed on irradiation by pulsed electron beam $\left(E_{\mathrm{S}}=10 \mathrm{~J} / \mathrm{cm}^{2}(a, b)\right.$, $\left.20 \mathrm{~J} / \mathrm{cm}^{2}(c, d), 30 \mathrm{~J} / \mathrm{cm}^{2}(e, f)\right)$ 


\begin{tabular}{|c|c|c|c|c|c|}
\hline \multicolumn{6}{|c|}{$\begin{array}{c}\text { Comparative data on layer thickness }(\mathrm{H}) \text { and surface substructure } \\
\text { size }(\mathrm{h}) \text { depending on energy density of electron beam }\end{array}$} \\
\hline $\begin{array}{c}\text { Characteristics } \\
\text { of columnar } \\
\text { structure }\end{array}$ & \multicolumn{5}{|c|}{ Energy density electron beam, $\mathrm{J} / \mathrm{cm}^{2}$} \\
\cline { 2 - 6 } & 10 & 15 & 20 & 25 & 30 \\
\hline $\mathrm{H}, \mu \mathrm{m}$ & $0,8-1$ & $9-10$ & 13 & $13-15$ & 20 \\
\hline $\mathrm{h}, \mu \mathrm{m}$ & $\begin{array}{c}\text { Not } \\
\text { revealed }\end{array}$ & $0.15-0.3$ & 0.3 & 1.0 & $2.5-3.0$ \\
\hline
\end{tabular}

electron beam of submillisecond duration effect. The relaxation of elastic stresses by microcrack formation is typical of ceramic materials and is indicative of increased brittleness of HEA under study.

The HEA irradiation by pulsed electron beam in mode of surface layer melting is accompanied by material homogenization as evidenced by release of grain boundaries from second phase precipitations. The increase in energy density of electron beam results in intensification of formation process of alloy homogeneous in elemental composition.

High-velocity crystallization of melted surface layer of HEA samples is accompanied by formation of submicronanocrystalline structure. The sizes of crystallites increase with growth of energy density of electron beam and vary at $\mathrm{E}_{\mathrm{S}}=30 \mathrm{~J} / \mathrm{cm}^{2}$ in the limits from $100 \mathrm{~nm}$ to $200 \mathrm{~nm}$.

The investigations into surface structure of brittle fracture of HEA samples modified by pulsed electron beam were carried out by the methods of scanning electron microscopy. It is established that the high-velocity crystallization of surface layer results in formation of columnar structure.

Thickness of modified layer $(\mathrm{H})$ increases from $0.8 \mu \mathrm{m}$ to $20 \mu \mathrm{m}$ in a regular way with increase in energy density of electron beam from $10 \mathrm{~J} / \mathrm{cm}^{2}$ to $30 \mathrm{~J} / \mathrm{cm}^{2}$ (Table).

Columnar structure is formed by crystallites whose sizes (h) increase in a regular way with growth of energy density of electron beam (Table).

It is detected that electron beam processing of alloy sample surface at different energy densities of electron beam resulted in the decrease in surface layer microhardness independent of processing parameters. The values decreased by on the average by $100 \mathrm{HV}$ in processed layer relative to material bulk. The least microhardness value was observed in processing mode with energy density of electron beam of $10 \mathrm{~J} / \mathrm{cm}^{2}$, it amounted to $368 \pm 1 \mathrm{HV}$ on the surface. The largest microhardness value of processed surface of $403 \pm 6 \mathrm{HV}$ was detected in the material processed with energy density of electron beam of $25 \mathrm{~J} / \mathrm{cm}^{2}$. It is established that electron beam processing results in change in surface layer microhardness to the depth up to $90 \mu \mathrm{m}$.

The results of investigations into nanohardness and elastic modulus of processed samples revealed a correlation with data on change in microhardness, namely, nanohardness and Young's modulus of surface layer decreased $28-30 \%$ on the average. The fact testifies that electron beam processing leads to relaxation of internal stress fields formed in the initial material on its manufacturing.

Electron beam processing affects slightly the friction coefficient and wear rate. The wear rate value of unprocessed sample amounts to $1.4 \times 10^{-4} \mathrm{~mm}^{3} / \mathrm{N} \cdot \mathrm{m}$, and in samples processed, by electron beam the values vary from 1.4 to $2.5 \times 10^{-4} \mathrm{~mm}^{3} / \mathrm{N} \cdot \mathrm{m}$. The friction coefficient amounts 0.65 for initial samples and $0.63-0.67$ for modified ones.

Irradiation of high-entropy alloy by intense pulsed electron beam led to an increase in strength and plasticity of the material. So, ultimate compression strength increased by 1.1-1.6 times. The largest ultimate compression strength value of was obtained in the alloy processed by electron beam with energy density of $30 \mathrm{~J} / \mathrm{cm}^{2}$.

\section{Conclusion}

Using the technology of wire-arc additive manufacturing (WAAM) the samples of high-entropy alloy $\mathrm{AlCoCrFeNi}$ of the following elemental composition ((wt. \%): $15.64 \mathrm{Al}$, 7.78 Co, 8.87 Cr, 22.31 Fe, 44.57 Ni) have been fabricated. It has been stated that deposited layers have a dendritic structure. Sizes of alloy grains vary in the limits from $4 \mu \mathrm{m}$ to $15 \mu \mathrm{m}$. Along boundaries and in the bulk of grains the second phase inclusions have been revealed. It has been determined by the methods of mapping that near-boundary bulks of the alloy (bulks located along grain boundaries) are enriched in chromium and iron atoms, the bulk of grains is enriched in nickel and aluminum atoms, cobalt is quasi-homogeneously distributed in the alloy. The melting temperature of obtained high-entropy alloy detected by the methods of thermogravimetric analysis is equal to $1495.18^{\circ} \mathrm{C}$.

It has been established that average microhardness values of samples amounts to $474 \pm 18 \mathrm{HV}$. The elastic modulus determined by the nanoindentation method amountsto $304 \pm 15 \mathrm{GPa}$. As a result of tribological tests it has been identified that HEA wear coefficient amounts to $1.4 \times 10^{-4} \mathrm{~mm}^{3} / \mathrm{N} \cdot \mathrm{m}$ and friction coefficient amounts to 0.65 . The results of the tests by the compression method have shown that ultimate strength of the material is within the range from 1300 to $1800 \mathrm{MPa}$.

It has been established that HEA irradiation by pulsed electron beam is accompanied by release of grain boundaries from the second phase precipitations that is indicative of material homogenization. In this case, the phase composition of the alloy is not changed. It has been shown that high velocity crystallization of molten surface layer of HEA samples is accompanied by formation of columnar structure having a submicro-nanocrystalline structure.

It has been determined that electron beam processing results in decrease in microhardness of alloy surface layer up to $90 \mu \mathrm{m}$ thick that may be caused by relaxation of internal field stresses formed in the initial material in manufacturing. It has been shown that HEA processing by pulsed electron beam affects slightly the friction coefficient and material wear rate. It has been revealed that irradiation of high-entropy alloy by intense pulsed electron beam results in the increase in strength and plasticity of the material. The ultimate compression strength increases $1.1-1.6$ times.

\section{Acknowledgements}

The research was supported by Russian Research Foundation grant (RSF) (project № 20-19-00452). 


\section{REFERENCES}

1. George E. P., Curtin W. A., Tasan C. C. High entropy alloys: A focused review of mechanical properties and deformation mechanisms. Acta Materialia, 2020. Vol. 188. pp. 435-474.

2. Shivam V., Basu J., Pandey V. K., Shadangi Y., Mukhopadhyay N. K. Alloying behaviour, thermal stability and phase evolution in quinary AlCoCrFeNi high entropy alloy. Advanced Powder Technology. 2018. Vol. 29. pp. 2221-2230.

3. Ganesh U. L., Raghavendra H. Review on the transition from conventional to multi-component-based nano-high-entropy alloys-NHEAs. Journal of Thermal Analysis and Calorimetry. 2020. Vol. 139. pp. 207-216.

4. Alshataif Y. A., Sivasankaran S., Al-Mufadi F. A., Alaboodi A. S., Ammar H. R. Manufacturing methods, microstructural and mechanical properties evolutions of high-entropy alloy: a review. Metals and Materials International. 2019. Vol. 26. pp. 1099-1133.

5. Cheng K. C., Chen J. H., Stadler S., Chen S. H. Properties of atomized $\mathrm{AlCoCrFeNi}$ high-entropy alloy powders and their phase-adjustable coatings prepared via plasma spray process. $A p$ plied Surface Science. 2019. Vol. 478. pp. 478-486.

6. Joseph J., Hodgson P., Jarvis T., WuX., Stanford N., Fabijanic D. M. Effect of hot isostatic pressing on the microstructure and mechanical properties of additive manufactured $\mathrm{Al}_{\mathrm{x}} \mathrm{CoCrFeNi}$ high entropy alloys. Materials Science and Engineering A. 2018. Vol. 733. pp. $59-70$.

7. Jian R., Wang L., Zhou S., Zhu Y., Liang Y.J., Wang B., Xue Y. Achieving fine-grain tungsten heavy alloys by selecting a high entropy alloy matrix with low W grain growth rate. Materials Letters. 2020. Vol. 278. p. 128405.

8. Hou L., Hui J., Yao Y., Chen J., Liu J. Effects of Boron Content on microstructure and mechanical properties of $\mathrm{AlFeCoNiBx}$ High Entropy Alloy Prepared by vacuum arc melting. Vacuum. 2019. Vol. 164. pp. 212-218.
9. Wu H., Huang S., Zhao C., Zhu H., Xie Z., Tu C., Li X. Microstructures and mechanical properties of in-situ $\mathrm{FeCrNiCu}$ high entropy alloy matrix composites reinforced with $\mathrm{NbC}$ particles. Intermetallics. 2020. Vol. 127. Pp. 106983.

10. Xu Y., Li C., Huang Z., Chen Y., Zhu L. Microstructure evolution and mechanical properties of $\mathrm{FeCoCrNiCuTi}_{0.8}$ high-entropy alloy prepared by directional solidification. Entropy. 2020. Vol. 22. pp. 1-12.

11. Miracle D. B., Senkov O. N. A critical review of high entropy alloys and related concepts. Acta Materialia. 2017. Vol. 122. pp. 448-511.

12. Zhang W., Liaw P. K., Zhang Y. Science and technology in highentropy alloys. Science China Materials. 2018. Vol. 61. No. 1. pp. 2-22.

13. Osintsev K. A., Gromov V. E., Konovalov S. V., Ivanov Yu. F., Panchenko I. A. HEA: structure, mechanical properties, mechanisms of deformation and application. Izvestiya. Ferrous Metallurgy. 2021. No. 4. pp. 1-10.

14. Rogachev A. S. Structure, stability and properties of high-entropy alloys. Physics of metals and materials science. 2020. Vol. 121. No. 8. pp. 807-841.

15. Ivanov Yu. F., Gromov V. E., Zagulyaev D. V., Konovalov S. V., Rubannikova Yu. A., Semin A. P. Prospects for the application of surface treatment of alloys by electron beams in state-of-the-art technologies. Progress in Physics of Metals. 2020. Vol. 21. No. 3. pp. 345-362.

16. Gromov V. E., Ivanov Yu. F., Vorobiev S. E., Konovalov S. V. Fatigue of steels modified by high intensity electron beams. Cambridge, 2015. $272 \mathrm{p}$.

17. Osintsev K. A., Konovalov S. V., Glezer A. M., Gromov V. E., Ivanov Yu. F., Panchenko I. A., Sundeev R. V. Research on the structure of $\mathrm{Al}_{2.1} \mathrm{Co}_{0.3} \mathrm{Cr}_{0.5} \mathrm{FeNi}_{2} .1$ high-entropy alloy at submicro- and nano-scale levels. Materials Letters. 2021. Vol. 294. p. 129717. 